\title{
Yenidoğan yoğun bakım ünitesinde gelişimsel destek
}

\author{
Zeynep Eras', Gülsüm Atay², Evrim Durgut Şakrucu'1, Emine Bahar Bingöler³, Uğur Dilmen ${ }^{4}$
}

\begin{abstract}
ÖZET:
Yenidoğan yoğun bakım ünitesinde gelişimsel destek

Son yıllarda tüm dünyada ve ülkemizde preterm doğumlar artmaktadır. Yenidoğan yoğun bakım alanındaki gelişmelere bağlı olarak preterm bebeklerde mortalitesi azalırken morbidite artmaktadır. Gelişimsel sorunlar en sık belirlenen morbiditelerdir. Artan morbiditenin azaltılabilmesi amacıyla kulIanılan gelişimsel yöntemlere gereksinim duyulmaktadır. Derlememizde gelişimsel sorunların azaltılmasına yönelik "yenidoğan yoğun bakım ünitesinde uygulanabilecek gelişimsel bakım yöntemleri" anlatılmaktadır.
\end{abstract}

Anahtar kelimeler: Gelişimsel bakım, preterm, yenidoğan yoğun bakım

\section{ABSTRACT:}

Developmental care in neonatal intensive care unit

The incidence of preterm births have increased worldwide and in our country in recent years. Related to advances in neonatal intensive care, the mortality of the preterm births decreases but the morbidity increases. Developmental problems comprise the main portion of the morbidity. Strategies and new approaches are needed to decrease the morbidity. This review is about the approaches of developmental care used in neonatal intensive care units to support the development of preterm babies.

Key words: Developmental care, preterm, neonatal intensive care

Ş.E.E.A.H. Tıp Bülteni 2013;47(3):97-103
'T.C.S.B. Dr. Zekai Tahir Burak Kadın Sağlığı Eğitim ve Araştırma Hastanesi, Gelişimsel Pediatri Ünitesi, Ankara-Türkiye

Başkent Üniversitesi, Tıp Fakültesi, Çocuk Sağlığı ve Hastalıkları Ana Bilim Dalı, Gelişimsel Pediatri Ünitesi, Ankara-Türkiye ${ }^{3}$ T.C.S.B. Ankara Çocuk Sağlığı ve Hastalıkları Hematoloji Onkoloji Eğitim ve Araştırma Hastanesi, Gelişimsel Pediatri Ünitesi, Ankara-Türkiye

${ }^{4}$ T.C.S.B. Dr. Zekai Tahir Burak Kadın Sağlığı Eğitim ve Araştırma Hastanesi, Yenidoğan Kliniği, Ankara-Türkiye / Yıldırım Beyazıt Üniversitesi Tıp Fakültesi, Çocuk Sağlığı ve Hastalıkları Ana Bilim Dalı, Ankara-Türkiye

Yazışma Adresi / Address reprint requests to: Zeynep Eras, T.C.S.B. Dr. Zekai Tahir Burak Kadın Sağlığı Eğitim ve Araştırma Hastanesi, Gelişimsel Pediatri Ünitesi, Ankara-Türkiye

E-posta / E-mail:

zeyneperas@yahoo.com

Geliş tarihi / Date of receipt: 1 Temmuz 2011 / June 1, 2011

Kabul tarihi / Date of acceptance: 7 Temmuz 2011 / June 7, 2011

\section{GíRiş}

Neonatoloji bilim alanındaki gelişmeler ve tedavi politikalarındaki değişikliklere bağlı olarak perinatal mortalite özellikle gelişmiş ülkelerde dramatik olarak azalmış, çok düşük doğum ağırlıklı (ÇDDA) bebeklerin yaşam oranları $\% 50$ 'den $\% 85^{\prime}$ e yükselmiştir $(1,2)$. Bununla birlikte preterm doğum oranı da özellikle batı sanayi toplumlarında giderek artmakta ve daha çok sayıda çok düşük gestasyonel yaşta bebek dünyaya gelmektedir. Amerika'da preterm doğumlar tüm doğumların \%12-13'üne ulaşmıştır $(3,4)$. Preterm bebeklerde azalan mortaliteyle birlikte pulmoner, nörolojik ve gelişimsel morbiditenin artması önemli sorunlar olarak karşımıza çıkmaktadır (5).

Dünya Sağlık Örgütü'nün 1980 yılındaki ‘engellilik' tanımına göre, ÇDDA bebeklerde yapılan uzun dönem çalışmalarda engellilik insidansının \%15-25 düzeyinde olduğu, \%5-10'unda serebral hareket bozukluğu geliştiği gösterilmiştir. Bu bebeklerin $\% 50$ ' sinden fazlasında dikkat eksikliği-hiperaktivite, görme sorunları, öğrenme güçlükleri, dil, duygusal ve sosyal alanlarda gelişimsel gecikme gibi gelişimsel sorunlar görüldügü vurgulanmaktadır. Bu çocukların 8 yaş civarında yaklaşık \%50'sinin çeşitli düzeylerde ek eğitim desteğine, \%20'den fazlasının ise kişisel bakım desteğine gereksinim duydukları bildirilmektedir (1,3,6-9). Çeşitli alanlarda yetersizliği olan bebeklerin ve çocukların sayılarının artması hem ailelerini olumsuz etkilemekte hem de okulda, evde ve çalışma alanlarındaki destekler için ilave kaynaklar gerektirmektedir (10).

Preterm bebeklerde nörolojik ve gelişimsel sorunlar intrakranial kanama, retinopati, sepsis, nekrotizan enterokolit gibi prematüriteye bağlı sorunların yanı sıra yeni doğan yoğun bakım ünitesinde ve taburcu- 
luk sonrasında bebeklerin yaşadıkları yoğun stres ile de ilişkilendirilmektedir. Stresin beyinin yapısını etkilediği radyolojik ve immünhistokimyasal yöntemlerle gösterilmiştir $(11,12)$. Erken doğumu takiben preterm bebek henüz beyin matürasyonunun kritik bir döneminde iken beyin gelişimi için doğal ortam olan sıcak, karanlık, sessiz, sakin, sıvı ile dolu anne rahminden ayrılarak gürültülü, parlak ışıklı ve hareketli yenidoğan yoğun bakım ünitesine (YYBÜ) yerleştirilir. Preterm bebekler; organizasyon sistemlerinin henüz tam gelişmemiş olması ve tamamlamamış olması ve gelişimi için uygun olmayan dış ortama geçmeleri nedenleriyle yoğun stres yaşarlar. Bu stres ve YYBÜ'ndeki parlak ışıklar, gürültü, sık uygulanan girişimlerin getirdiği duyusal deneyimlerin prematür bebeğin beynindeki hücre göçü, sinaptogenez, myelinizasyon ve organizasyon yapılarının gelişimini olumsuz etkilediği, düzenini bozduğu düşünülmektedir $(8,9,13)$.

Yenidoğan yoğun bakımının esası; prematür bebeğin solunum, kalp, gastrointestinal, böbrek, bağışıklık ve dermatolojik sistemlerinin desteklenmesidir. Bununla birlikte nörolojik ve gelişimsel sorunların sıklığının değerlendirilmesi yenidoğan yoğun bakımının etkinliğini değerlendirmede önemli bir ölçüt haline gelmiştir. Bu durum nörolojik ve gelişimsel sorunları azaltmaya yönelik nöroprotektif stratejilerin ve gelişimsel destek yaklaşımlarının (Developmental Care) gerekliliğini gündeme getirmiştir $(10,14)$.

Nöroprotektif stratejiler; santral sinir sistemini korumak veya iyileştirmek amacı ile, uygulanan ilaç tedavileri ( intraventriküler kanamayı önlemek amacryla indometazin verilmesi) veya solunum ve kardiyovasküler sistemi destek tedavilerini (hiperventilasyondan kaçınma, kan basıncının dengelenmesi) düzenlemektir (14).

Gelişimsel bakım (Developmental Care); yenidoğan yoğun bakımında, yenidoğan yoğun bakım ünitesi (YYBÜ) ortamının, YYBÜ ve taburculuk sonrası verilen bakımın prematüre bebeğin nörolojik matürasyonunu desteklemeye yönelik düzenlemelerin yapılmasıdır (13). Bu düzenlemeler bebeğin çeşitli uyaranlara karşı verdiği fizyolojik cevapların ve davranış işaretlerinin gözlemine dayanarak stres yaratan uyaranların azaltılmasını, gelişimini destekleyici uya- ranların sağlanmasıdır.

Gelişimsel bakım başlığı altında yer alan yaklaşımlar şunlardır $(8,13,14)$ :

1) Çevresel ışık ve sesin kontrolü

2) Bakım programlarının oluşturulması

3) Ailenin katılımının sağlanması

4) Besleyici olmayan emmenin desteklenmesi

5) Prematüre bebek masajı uygulaması

6) Kanguru bakımı uygulaması

7) Yenidoğanın bireyselleştirilmiş gelişimsel bakım ve değerlendirme programı-YBGBDP (Newborn Individualized Developmental Care and Assessment Program- NIDCAP)

\section{1.) Çevresel Işık ve Sesin Kontrolü}

Yenidoğan yoğun bakım ortamındaki ışığın, bebeğin fizyolojik stabilite ve santral sinir sisteminin organizasyonu üzerine direkt etkisi vardır. YYBÜ'ndeki bu görsel çevrenin; görsel aktiviteyi azalttığı, görsel işleme koyma ile ilgili problemlere yol açtığı, görsel dikkat-algılama, görsel hafıza ve görsel ayırt etmeyi değiştirdiği belirtilmektedir (8). Günün belli saatlerinde ışık düzeylerinin azaltılmasının kalp hızında ve aktivitede azalmaya neden olduğu, biyolojik ritmi güçlendirdiği, dinlendirici uykuyu arttırdığı, beslenmeyi iyileştirdiği, kilo alımını ve bebeğin çevreyle ilgisini arttırdığı bildirilmektedir (8). YYBÜ ortamında uygun ve güvenli aydınlatma düzeyleri tam netliğe kavuşmamıştır ancak ışığı azaltmaya yönelik çabalar gelişimsel desteği ve güvenli bakımı sağlamanın önemli bir bölümünü oluşturur (1).

YYBÜ'nde aydınlatma ile ilgili öneriler şöyle sıralanabilir $(1,8,14)$ :

1) Çeşitli uygulamalar dışında bebeğin bulunduğu alana direkt ışık gelmesinin engellenmesi

2) Kuvözler için hazırlanmış örtüler gibi çeşitli seçeneklerle ışığın azaltılmasının sağlanması

3) Günün belirli saatlerinde ışık düzeylerinin değiştirilmesi ile gündüz-gece döngülerinin sağlanması ve bu sayede bebeğin REM uykusunun desteklenmesi

4) Aydınlatma araçlarının düzeylerinin bilinmesi ve bebeğin ışığa maruziyetinin azaltılması

Aşırı sese duyarlılık gestasyonel 6. ayda başlar ve doğumdan sonraki 2-3. aya kadar devam eder. Pre- 
term bebeklerde aşırı gürültü ve yüksek sese bağlı işitme kaybı gelişebileceği gibi, sesle ilişkili bir dizi fizyolojik ve davranış değişikliklerini içeren stres reaksiyonu da ortaya çıkabilir $(1,8)$. Ses düzeylerinin azaltılmasına yönelik girişimler YYBÜ'deki gelişimsel destek yaklaşımlarının önemli bir parçası olarak görülmektedir. YYBÜ'nde ses ile ilgili öneriler şöyle sıralanabilir $(1,8)$ :

a. Bebeğin bakım alanında gürültünün azaltılması

b. Ses düzeylerinin $50 \mathrm{~dB}^{\prime} \mathrm{i}$ geçmemesi

c. Geçici seslerin 70dB'i geçmemesi

d. Ortamdaki ekipmanların gürültü düzeylerinin $40 \mathrm{~dB}^{\prime} \mathrm{i}$ geçmemesi

e. YYBÜ'nde gürültünün azaltılmasını sağlayan ve bu yönde yoğun bakım çalışanlarını eğiten bir ekibin olması

\section{Bakım Programlarının Oluşturulması}

Fetüs, intrauterin ortamda sıcak, sıvı ile dolu bir ortamda yaşar ve amniyotik sıvının sabit titreşimleri ile nazikçe sallanarak uyur. Olması gerekenden erken geldiği dış ortam ise bundan çok daha farklı, daha serttir ve bebek için bazen çok zorlayıcı ve stres yaratıcıdır. Bebek her dokunmayı ağrı olarak hissedebilir ve buna kıvranma, ağlama, ellerini ve ayaklarını geri çekme ya da tepme gibi davranışlarla karşılık verebilir $(1,13)$. Nazikçe kavramanın, bebekte ani postür değişikliklerinden kaçınmanın, bebeğin taktil ve vestibüler gelişimini desteklemeye yardımcı olduğu düşünülmektedir. Bunlara ek olarak kan örneklerinin alınması, görüntüleme yöntemleri, aspirasyon, göğüs fizyoterapisi gibi işlemlerin koordine edilmesi ve bebeğe yeterli sessiz ve dinlenme zamanlarının sağlanması gelişimin desteklenmesi yönünde çok önem taşımaktadır $(1,13)$.

\section{Ailenin Katılımının Sağlanması}

Çalışmalarda prematüre doğmuş çocuklarda nörolojik, duyusal veya hareket alanlarında belirgin bozukluk olmamasına karşın bilişsel, konuşma ve dil, davranış, sosyal ve duygusal gelişimsel sorunların ve okul problemlerinin sık görüldüğü bildirilmektedir (15). Preterm doğumla bebeğin anneden erken ayrılmasının, anne-bebek ilişkisinin gelişimini olumsuz etkilediği gösterilmiştir (16). Preterm bebekler ve anneleri arasındaki iletişim stilleri ile zamanında doğmuş bebekler ve anneleri arasındaki iletişim stilleri arasında bir takım farklılıklar belirlenmiştir. Bu farkın; bebeğin immatüritesine, prematüre bebeğin ebeveynlerinden erken ayrılma deneyimine ve annenin perinatal dönemde yaşadığı travmatik stres ve duygusal deneyimlerine bağlı olduğu düşünülmüştür $(17,18)$. Preterm bebeklerin zamanında doğan bebeklere göre daha az düzeyde uyanık, dikkatli, aktif, uyumlu oldukları ve etkileşime daha az cevap verdikleri, annelerinin ise daha aktif, uyarıcı, zorlayıcı, bebeklerinin gereksinimlerine daha az duyarlı, onlarla daha mesafeli ve kontrolcü davranışlar gösterdikleri belirtilmektedir. Annelerin tutumları genellikle 18 ay civarında düzelmekle birlikte çocukların anneleriyle ilişkide daha pasif, zorlayıcı ve keyifsiz olmaya devam ettikleri bildirilmektedir (17).

Çalışmalar preterm doğumun anne-bebek etkileşiminin kalitesini ve çocuğun ileri dönemdeki gelişimini olumsuz yönde etkilediği de gösterilmiştir $(15,18,19)$. Ailenin preterm doğumun yarattığı koşullara adapte olma becerisi ve erken oluşturulan ebeveyn-bebek ilişkisinin kalitesinin bebeğin daha sonraki dönemlerde becerileri ve gelişimi açısından kritik önem taşıdığı savunulmaktadır (15,17-21). Olumlu ve erken anne-bebek etkileşiminin, 1 yaşta bebeğin annesiyle daha güvenli bir ilişki oluşturmasını, okul öncesi dönemdeki davranış sorunlarının sıklığını azalttığı ve okul döneminde bilişsel gelişimi olumlu etkilediği belirlenmiştir $(15,19)$.

Annenin bebeğine bakım verme deneyimlerini ve onunla sosyal iletişimini arttırmaya yönelik yenidoğan yoğun bakım uygulamalarının ve girişimlerinin geliştirilmesi erken dönemde olumlu anne- bebek etkileşiminin kurulmasına yardımcı olmaktadır. Yoğun bakımdaki sağlık çalışanlarının ve diğer çalışanların annenin bebeğin bakımını üstlenmede kendine güvenini arttırmaları ve bebeği ile daha iyi ilişki kurmasını güçlendirmek için onun davranışlarını değerlendirmede iyi bir gözlemci olmasına yardımcı olması bu girişimlerin en önemli bileşenidir. Bu girişimlerin ilk hedefi annenin bebeğini olumlu algılamasının sağlanmasıdır. Daha sonra annenin bebeğini tutması, bakım vermesi ve gözlemlemesi konusunda fırsat vermek ve onun çevresel uyaranlara tepkilerine 
duyarlı ve olumlu tepkiler vermesini sağlamaya çalışılmaktadır. Böylece annenin kendine güveni, bebeğin verdiği tepkileri okumadaki yeteneği ve bebeğin davranışlarına uygun cevap verme becerisi arttırılmaktadır (15,17-19).

\section{Besleyici Olmayan Emme}

Emmenin erken bileşenleri fetal hayatta 7-8. haftalarda ortaya çıkmaktadır, emme ve yutma 28 . gestasyonel hafta itibariyle bulunmakla birlikte 32-34. haftaya kadar tam anlamıyla düzenli değildir (22). Prematüre bebeklerde emme davranışının gelişiminin, nörolojik ve davranış alanında matürasyon ve organizasyonu yansıttığı düşünülmektedir. Klinik bakış açısıyla bakıldığında, beslenme becerisi; emme-yutma ve solunum paternlerinin koordinasyonuna bağlıdır ve 32. gestasyonel haftanın altında doğmuş bebeklerde bu beceri tam ağızdan beslenmeyi sağlayacak yeterlilikte değildir. Bu nedenle preterm bebekler anne göğsünden veya biberondan direkt olarak beslenebilmeleri için yeterli olgunluğa ulaşana kadar gastrik tüp ile beslenirler $(1,14,22)$. Gastrik tüple beslenme sırasında ve tüpten anne memesine veya biberona geçiş aşamasında emme davranışını geliştirmesi ve enteral besinlerin sindirimini düzeltmesi amacıyla besleyici olmayan emme kullanılmaktadır $(22,23)$. Bunlara ek olarak besleyici olmayan emme bebeğin üzerinde sakinleştirici ve rahatlatıcı bir etkiye sahiptir (22).

Çalışmalar besleyici olmayan emmenin; preterm bebeklerin hastanede kalış süresini kısalttığını, tam ağızdan beslenmeye geçişi hızlandırdığını ve genel beslenme performansını arttırdığını göstermektedir (22). Ayrıca, stres yaratan bir durum olan gastrik tüple beslenme sırasında sakin kalarak daha az karşı koyucu davranış sergilemektedirler, beslenme sırasında sonrasında daha hızlı sakinleşerek uykuya dalmaktadırlar $(1,22)$.

\section{Prematüre Bebekte Masaj tedavisi}

Fetusun ve yenidoğanın gelişimin hassas dönemler içerdiği ve bu dönemlerde santral sinir sisteminin en uygun gelişimi için belirli uyaranlara ihtiyaç duyulduğu savunulur. Dokunma; fetal dönemde en erken gelişen duyudur ve görme, işitme gibi duyusal gelişim basamaklarının öncülüğünü yapar ve hemen doğumdan sonraki dönemde önemli çevresel girdilerdendir. Preterm doğum bebeği koruyucu ve bakım veren annesinin rahminden ayırmakla kalmaz aynı zamanda annenin yakınlığı ve temasının yararlarından da uzaklaştırır. Masaj tedavisinin, bu önemli "hassas dönemde " erken ayrılmanın zararlı etkilerini azalttığı ve bebeğin kendini yatıştırabilme ve sosyal ilişki kurma becerisini düzelttiği düşünülmektedir $(24,25)$. Masaj tedavisi karmaşık tıbbi problemleri olan bebeklere bile uygulanabilmekte ve ailelerin kendi bebeklerinin bakımına katılmalarına olanak sağlamaktadır (25).

Randomize kontrollü çalışmalarda masaj tedavisi ve yumuşak taktil uyarının prematüre bebeklerde stresi azalttığı, bebeğin büyümesini desteklediği, uyku-uyanıklık döngüsünün olgunlaşmasını güçlendirdiği, hastanede kalış süresini kısalttığı, annelerdeki doğum sonrası depresyonu azalttığı, preterm bebeklerin annelerinde görülen zorlayıcı tutumları azalttığı ve anne ile bebek arasındaki ilişkiyi iyileştirdiği gösterilmiştir $(16,24)$. Masaj anne tarafından uygulanmasa da benzer olumlu etkilere neden olmaktadır. Preterm bebeklerin daha uzun süreler uyanık kalmasını sağlayarak bebeğin ilişki kurmadaki pasifliğini azaltmakta, çevresi ve annesiyle daha erken, sık ve güçlü ilişki kurmasını sağlamaktadır (24).

\section{Kanguru bakımı}

Kanguru bakımı ilk kez Bogota (Colombia)'da 1978 yılında Dr. Edger Rey Sanabria tarafından çok düşük doğum ağırlıklı bebeklerde yüksek mortalite ve morbiditeye rağmen yenidoğan yoğun bakım ünitelerinin çok kalabalık olması ve kaynakların yetersiz olmasıyla başlatılmıştır (26). Morbiditeyi ve mortaliteyi azaltması erken dönemde aileyi bebeklerinin bakımına katarak aileyi ve özellikle anneyi ve anne bebek ilişkisini güçlendirebildiği, emzirmeyi olumlu etkilediği için düşük doğum ağırlıklı bebeklerde konvansiyonel yenidoğan bakımına alternatif olarak önerilmektedir $(26,27)$. Kanguru bakımında bebekler, kanguru pozisyonu denilen annenin göğüsleri arasında ve giysilerinin altında, vertikal pozisyonda yatırı- 
larak bebek ve annenin cilt cilde teması sağlanır. Uygulama mümkün olan en erken zamanda hatta doğum salonlarında veya yenidoğan yoğun bakım ünitesinde başlatılmalı ve en kısa zamanda anne bebeğin ayrılmasına son verilmelidir (26). Kanguru bakımında annenin vücudu, sesi, kokusu, taktil uyarısı ile çevresel stresi azalttı̆̆ı ve bebeğin santral sinir siteminin matürasyonunu olumlu etkilediği düşünülmektedir $(26,27)$. Johnson ve ark. (27) çalışmalarında tek başına Kanguru bakımı ile yapılan taktil uyarı, koku, dokunma gibi duyusal uyarının prematüre bebeklerde ağrıyı azalttığını belirlemişlerdir.

Kanguru pozisyonunun etkileri pek çok çalışmayla değerlendirilerek olumlu etkileri gösterilmiştir. Çalışmaların sonuçları şöyle özetlenebilir:

Kanguru bakımı uygulanan bebeklerin doğum sonrasında vücut ısıları hızla yükselmekte ve yoğun bakım sürecinde uygun ısıda kalabilmektedirler. Hemen sakinleşerek ve rahatladıkları, kolay uykuya daldıkları, uyanık dahi olsalar sakin kaldıkları görülmektedir. Bebeklerin kilo alımı olumlu etkilemekte, emzirmenin süresi uzamakta ve anne sütü alım miktarı artmaktadır. Anne babalar prematüre doğumla birlikte ortaya çıkan şokun ve stresin daha kolay ve hızlı üstesinden gelmektedirler. Bebeklerinin sağlık durumları konusunda daha erken sorumluluk hissetmeye başlamaktadırlar. Annelerin yeterlilik duygusu ve annelik rolüne adaptasyonu artmakta ve bebeklerine bağlanmalarıgüçlenmekte, bebeklerinin ihtiyaçlarına daha duyarlı olmalarını ve daha uyarıcı ev ortamı sağlamalarını sağlamaktadır $(26,27)$.

\section{Yenidoğanın Bireyselleştirilmiş Gelişimsel Bakım ve Değerlendirme Programı-YBGBDP}

Yenidoğanın Bireyselleştirilmiş Bakım ve Değerlendirme Programı - YBGBDP (Newborn Individualized Developmental Care and Assessment ProgramNIDCAP) Heidi Als tarafından 1980 yılında geliştirilmiştir. Yenidoğan döneminde bebeğe uygun uyaranı sağlayarak ve bebek ve anne babası arasındaki ilişkiyi güçlendirerek onun nörolojik maturasyonunu hızlandırmayı amaçlayan aile merkezli erken destek programıdır. Program yenidoğan yoğun bakım ortamının ÇDDA bebeğin bireysel fizyolojik gereksinimlerine göre düzenlenmesinin stresi azaltarak beyin gelişimini olumlu etkileyeceği hipotezine dayanmaktadır $(7,28)$.

Bebeğin yoğun bakım süresinde işitme, görme ve dokunma gibi duyusal uyaranların kontrolü, bebeğin tutulma, yatma, kundaklanma şeklinin iç deneyimine benzer şekilde gerçekleştirilmesi, yoğun bakım tedavilerinin mümkün olduğunca bebeğin gereksinimlerine göre planlanması gibi pek çok öğe bu programın parçalarıdır (7).

Bu programın birinci aşamasında bebek beslenme, alt değiştirme, kan örneklemelerinin toplanması gibi bakım işlemleri öncesinde, işlemler sırasında ve sonrasında 20 dakika süre gözlenir. Gözlem sırasında genel durum, otonom, hareket, dikkat ve kendini yatıştırabilmesi açısından 5 alanda değerlendirilir. Genel durum değerlendirmesinde bebeğin uyku uyanıklık hali, rahatlık - huzursuzluk durumu; otonom sistem değerlendirilmesinde nefes alma özellikleri, cilt rengi, idrar-dışkı akışı; hareket sistemi değerlendirilmesinde tonüs, postur ve hareketleri incelenir. Dikkat alanında bebeğin uyanık ve ilgili bir duruma gelebilme becerisi ve çevreden uyaranı alabilmek için bu durumu sürdürebilme yeteneği değerlendirilir. Bebeğin barsak hareketleri gibi içsel ve ışık, ses, dokunma gibi dışsal duyusal uyaranlara verdiği davranış tepkileri not edilir ve analiz edilir. Tekrarlayan gözlemlerle bebeğin bireysel davranış özellikleri ve gereksinimleri iyice anlaşılır $(5,7,28)$. Programın ikinci aşamasında benzer gözlemlerle yoğun bakım ortamının bebeğin üzerine olan etkisinin anlaşılmasına çalışılır ve bireyselleştirilmiş bakım ve çevresel değişiklikler konusunda bebeğe uygun bakım önerileri şekillendirilir $(7,8)$. Bu bakım planı aile ve yoğun bakım personeli ile tartışı।ır, bu şekilde kırılgan bebeğin immatür tepkilerini yorumlama ve bunlara uygun bakımı vermek için yoğun bakım personeline ve aileye gerekli beceriler kazandırılır. Tüm bu süreçte aile mutlaka yoğun bakım ekibinin bir parçasıdır, karar ve uygulamalara etkin olarak katılır (8).

YBGBDP programının yenidoğan yoğun bakım sürecindeki etkileri ile ilgili çalışmalarda programın uygulandığı bebeklerin mekanik ventilasyon süresinde kısalma, oksijen ihtiyacı gün sayısında, kronik akciğer hastalığı gelişimi sıklığında azalma $(29,30)$, total parenteral beslenme süresi ve tam enteral beslenmeye geçiş süresinde kısalma, nekrotizan entero- 
kolit gelişmesi sıklığında azalma; kilo-boy ve baş çevresinin büyüme hızında artış; otonom-motorgenel durum -dikkat ve self regülasyon işlevlerinde güçlenme (31), rutin hemşire uygulamaları sırasında ağrı cevabının ve strese bağlı gelişen hipoksik sürecin azaldığı, bebeklerin uyku süresinin arttığı $(32,33)$, yoğun bakım ve hastanede kalış süresinde kısalma bildirilmiştir (29-31). Ayrıca ailelerin daha az stresli oldukları da belirlenmiştir (31).

Program uygulanan bebeklerde postnatal düzeltilmiş 2. haftada yapılan EEG, spectral coherence, ve MRI difüzyon tetkikleri ile çalışma grubunda kontrol grubuna göre daha iyi nörolojik ve davranışsal sonuçların elde edilmesinin yanısıra, frontal ve oksipital beyin alanları arasında uyumda (yapışma) artış belirlenmiştir (34).

YBGBDP programının bebeklerin gelişimine etkileri ile ilgili çalışmalarda programın uygulandığı bebeklerin 'Bayley Bebekler için Gelişimsel Değerlendirme Ölçeği' ile yapılan değerlendirmede 9 . ayda bilişsel ve hareket ölçek puanlarının (34-36), 12. ayda bilişsel ölçek puanlarının daha yüksek olduğu bildirilmiştir $(28,29)$. Programın uygulandığı bebeklerde 1 yaşta bilişsel ölçek puanları >80 olanların 7 kat daha fazla olduğu belirlenmiştir (28). Programın uygulandığı çocukların dil gelişimi, davranışları ve anne-bebek etkileşimleri olumlu etkilenmekte, çocuklar duygularını daha iyi ifade edebilmekte,

\section{KAYNAKLAR}

1. Sizun F, Westrup B. Early developmental care of preterm neonates: a call for more research. Arch Dis Child Fetal Neonatal Ed 2004;89:384-9.

2. Ward RM, Beachy JG. Neonatal complications following preterm birth. BJOG 2003;110(Supply.20):8-16.

3. Fawke F. Neurological outcomes following preterm birth. Semin Fetal Neonatal Med 2007;12(5):374-82.

4. Alien MC. Neurodevelopmental outcomes of preterm infants. Curr Opin Neurol 2008;21(2):123-8.

5. Westrup B. Newborn individualized developmental care and assessment program (NIDCAP) -Family centered developmentally supportive care. Early Hum Dev 2007;83(7):443-9.

6. Wen SW, Smith G, Yang Q, Walker M. Epidemiology of preterm birth and neonatal outcome. Semin Fetal Neonatal Med 2004;9(6):429-35.

7. Kleberg A, Westrup B, Stjernqvist K. Developmental outcome, child behavior and mother-child interaction at 3 years of age following Newborn Individualized Developmental Care and Interaction Program (NIDCAP) Intervention. Early Hum Dev 2000;60(2):123-35. anneler ise bebekleri ile daha iyi fiziksel ve göz teması kurabilmektedirler (7).

YBGB programının olumlu etkilerinin programın: 1) perinatal dönemde bebeğin otonom sisteminde stabilizasyonu sağlayarak beyin hasarını azaltmasına; 2) bebeğin beyin gelişimi için gerekli en uygun çevreyi sağlamasına; 3) bebeğin gelişim evresine göre uygun düzeyde dış uyaranlar sunmasına; 4) aile, hemşireler ve doktorlar dahil tüm bakım veren kişilerin bebeğe karşı daha duyarlı olmasını sağlayıp onu daha iyi anlamalarını sağlayarak doğru ve yeterli uyaranı verecek beceriyi kazandırmasına; 5) Taburculuk sonrasında bebeği iyi tanıyan ve anlayan anne babasının onun gelişimini en iyi şekilde destekleyen uyaranları ve çevresel koşulları sağlamasına bağlı olduğu ileri sürülmektedir $(1,5,14)$.

Tüm dünyada ve ülkemizde yardımcı üreme tekniklerinin çeşitliliğinin ve yaygınlığın artması, gebelik sırasında anneye verilen sağlık hizmetinin kalitesinin ve yaygınlığının artmasıyla preterm doğumlar da artış göstermektedir (37). Ülkemizde yenidoğan yoğun bakım merkezlerinin yaygınlaşması, bu alanda özel eğitim almış hekim ve diğer sağlık çalışanlarının artmasıyla birlikte preterm bebeklerde mortalite giderek azalacak ve artan morbiditenin azaltılabilmesi amacıyla kullanılan gelişimsel bakım yöntemlerine gereksinim de artacaktır. Bu alandaki uygulamaların ve gelişmelerin izlenmesi gerekliliği doğmaktadır.

8. Vanderburg KA. Individualized developmental care for high risk newborns in the NICU: A practice guideline. Early Hum Dev 2007;83(7):433-42.

9. Wielenga JM, Smit BJ, Merkus MP, Wolf MJ, Sonderen L, KokJH. Development and growth in very preterm infants in relation to NIDCAP in a Dutch NICU: two years of follow-up. Acta Paediatr 2009;98(2):291-7.

10. Costella DW, Friedman $H$, Minich $N$, Siner B, Taylor $G$, Schluchter M, Hack M. Improvement neurodevelopmental outcomes for extremely low brith weight infants in 2000-2002. Pediatrics 2007;119(1):37-45.

11. National Scientific Council on the Developing Child (2005). Excessive Stress Disrupts the Architecture of the Developing Brain: Working Paper \#3. http://www.developingchild.net

12. Shansky RM, Morrison JH. Stress-induced dendritic remodeling in the medial prefrontal cortex: effects of circuit, hormones and rest. Brain Res 2009;1293:108-13.

13. Sehgal A, Stack J. Developmentally supportive care and NIDCAP. Indian J Pediatr 2006;73(11):1007-110. 
14. Aucott S, Donohue PK, Atkins E, Allen MC. Neurodevelopmental Care in NICU. Ment Retard Dev Disabil Res 2002;8(4):298 $-308$.

15. Forcada-Guex M, Pierrehumbert B, Borghini A, Moessinger A, Mulller-Nix C. Early dyadic patterns of mother-infant interactions and outcomes of prematurity at 18 months. Pediatrics 2006;118(1):e107-e114.

16. Ferber SG, Feldman R, Kohelet D, Kuint J, Dollberg S, Arbel E, Weller A. Massage therapy facilities mother-infant interaction in premature infants. Infant Behav Dev 2005;28:74-81.

17. Muller-Nix C, Forcada-Guex M, Pierrehumbert B, Jaunin L, Borghim A, Ansermet F. Prematurity, maternal stres anf motherchild interactions. Early Hum Dev 2004;79(2):145-58.

18. Feldman R. Parent-infant synchrony and the construction of shared timing; physcological precursors, developmental outcomes and risk conditions. J Child Psychol Psychiatry 2007;48(314):329-54.

19. Schermann-Eizirik L, Hagekull B, Bohlin G, Perrson K, Sedin G. Interaction between mothers and infants born at risk during the first 6 months corrected age. Acta Paediatr 1997;86(8):864-72.

20. Foster-Cohen SH, Friesen MD, Champion PR, Woodward LJ. High prevalence/low severity language delay in preschool children born very preterm. J Dev Behav Pediatr 2010;31(8): 658-67.

21. Spittle AJ, Anderson PJ, Lee KJ, et al. Preventive care at home for very preterm infants improves infant and caregiver outcomes at 2 years. Pediatrics 2010;126(1):e171-178.

22. Pinelli J, Symington A. Non-nutritive sucking for promoting physcologic stability and nutrition in preterm infants. Cochrane Database Syst Rev 2005;(4):CD001071.

23. Pimenta HP, Moreira ME, Rocha AP, Gomes SC, Pinto LW. Effects of non-nutritive sucking and oral stimulation on breastfeeding rates for preterm, lowbirth weight infants: a randomized clinical trial. J Pediatr (Rio J) 2008;84(5):423-7.

24. Vickers A, Ohlsson A, Lacy JB, Horsley A. Massage for promoting growth and development of preterm and/or low birth weight infants. Cochrane Database Syst Rev 2004;(2):CD000390.

25. Livingstone K, Beider S, Kont AJ, Gallardo CC, Joseph MH, Gold Jl. Touch and massage for medically fragile infants. Evid Based Complement Alternat Med 2007;6(4):473-82.

26. Cande-Agudelo A, Diaz-Rossello JL, Belizan JM. Kangaroo mother-care to reduce morbidity and mortality in low birth weight infants. Cochrane Database Syst Rev 2003;(2):CD002771.
27. Johnston CC, Filion F, Campbell-Yeo M, Goulet C, Bell L, MC Naughton K, Byron J. Enhanced Kangaroo mother-care for heel lance in preterm neonates: a crossover trial. J Perinatol 2009;29(1):51-6.

28. Kleberg A, Westrup B, Stjernqvist $K$, Langercrantz $H$. Indications of improved cognitive development at one year of age among infants born very prematurely who received care based on the Newborn Individualized Developmental Care and Assesment Program (NIDCAP). Early Hum Dev 2002;68(2):83-91.

29. Marret C, Arcel PY, Marpeu L et al. Neonatal and 5 years outcomes after birth of 30-34 weeks of gestation. Obstet Gynecol 2007;110(1):72-80.

30. Peters KL, Rosychuk RJ, Hendson L, Cote JJ, McPherson C, Tyebkhan JM. Improvement of short- and long-term outcomes for very low birth weight infants: Edmonton NIDCAP trial. Pediatrics 2009; 124(4):1009-20.

31. Als H, Gilkerson L, Duffy FH, et al. A three center, randomized, controlled trial of individualized developmental care for very low birth weight preterm infants: medical, neurodevelopmental, parenting and care giving effects. I Dev Behav Pediatr 2003;24(6):399-408

32. Sizun J, Ansquer H, Brpwre J, Tordjman S, Morin JF. Developmental care decreases physicologic and behavioral expression in preterm neonates. J Pain 2002;2:446-50.

33. Bertelle V, Mabin D, Curzi-Dascolova L, Adrien J, Sizun J. Sleep of preter neonates under developmental care or regular environmental conditions. Early Hum Dev 2005;81:595-600.

34. Als H, Duffy M FH, McAnulty GB. Effectiveness of individualized neurodevelopmental care in the newborn intensive care unit (NICU). Acta Paediatr Suppl 1996;416:21-30.

35. Als H, Lawhom G, Brown E, Gibes R, Duffy FH, et al. Individualized behavioral and environmental care for the very low birth weight preterm infant at high risk for bronchopulmonary dysplasia: NICU and developmental outcome. Pediatrics 1986;78:1123-32.

36. Als H, Lawhon G, Duffy FH, McAnulty EB, Gibes-Grossman R. Individualized developmental care for the very low birth weight infant. JAMA 1994;272:853-8.

37. Türk Neonatoloji Derneği Yardımlı Üreme Teknikleri ve Çoğul Gebelikler Çalışma Grubu. Yardımli üreme tekniklerinin neontal mortalite ve morbidite üzerine etkileri. Çocuk Sağlığı ve Hastalıkları Dergisi 2010;53:258-66. 